\title{
Geographic variation in social organization of Galápagos mockingbirds: ecological correlates of group territoriality and cooperative breeding
}

\author{
Robert L. Curry * \\ Department of Biology, The University of Michigan, Ann Arbor, MI 48109, USA \\ Received April 18, 1988 / Accepted March 21, 1989
}

Summary. To investigate ecological influences on cooperative social organization, I studied the four allopatric species of mockingbirds (Nesomimus spp.) endemic to the Galápagos archipelago on four islands. On three small, low and arid islands (Genovesa, Champion and Española), mockingbird territories filled all terrestrial habitat, mean group size varied from 4.5 to 14.2 adults, maximum group size ranged from seven to 24 birds, and $70-100 \%$ of groups contained more than two birds. San Cristóbal is larger and higher, and it supports a broader range of habitats. At one highland and two coastal sites on this island, mockingbirds did not hold territories in all available habitats, group size averaged 2.2 adults, only $25 \%$ of groups were larger than two, and none included more than three adults. Adults dispersed into vacant habitat to establish new territories only on San Cristóbal. Helping behavior has not yet been observed on San Cristóbal, but it occurs on the other three islands. These results support the hypothesis that social groups and cooperative breeding are maintained where limited availability of preferred habitat constrains dispersal. The mechanism relaxing habitat saturation on San Cristóbal, however, remains undetermined. Predation by introduced rats and cats may reduce survival and indirectly reduce group size; these predators are absent from Genovesa, Champion and Española. Differences in food supplies could also affect interand intra-island variation in population density. Variation in social organization among arid coastal sites on the four islands, and similarity between climatically different sites on San Cristóbal, suggest that climatic conditions are less important as

\footnotetext{
* Present address: Archbold Biological Station, Lake Placid, FL 33852-2057, USA
}

determinants of dispersal and breeding. Skews in adult sex ratios also fail to account for inter-island variation in sociality. Although they live in a climatically variable environment, territorial behavior and the physical limits of suitable habitat have an overriding influence on cooperative social organization in Galápagos mockingbirds.

\section{Introduction}

Cooperative breeding occurs when more than two individuals participate in reproduction (Emlen and Vehrencamp 1983) and some individuals act as helpers, caring for young other than their own offspring (Brown 1987). A central question about cooperative breeding concerns the mechanisms of natural selection by which helping has evolved. Among birds, however, helping is usually performed by young nonbreeders remaining in their natal social groups (see Stacey and Koenig 1989). Delayed dispersal and breeding therefore can be considered preconditions for the development of cooperative breeding. (Delayed breeding by itself, however, is not always a prerequisite: breeders can also act as helpers if groups contain more than two breeders [Brown and Brown 1980; Faaborg and Patterson 1981; Curry 1988a, b]). To understand how cooperative breeding systems are maintained, it is therefore necessary to determine how ecological factors, by favoring delays in dispersal and breeding, cause stable social groups to persist. Why birds help, once their dispersal and breeding have been delayed, can be considered a partially independent question (Brown 1987; Koenig and Mumme 1987; Curry 1988 a).

Ecological variables ultimately can operate only through effects on demography: individuals 
must gain higher lifetime inclusive fitness by delaying dispersal than by leaving their natal groups (Brown 1978, 1987; Emlen 1982; Stacey and Ligon 1987). Five hypothesized mechanisms have been central to discussions of cooperative breeding. (1) Limited availability of different habitats, and the territorial behavior of established breeders, could prevent some individuals from gaining high quality breeding space (Selander 1964; Brown 1969, 1974, 1978). Individuals would remain in their natal groups if the odds of surviving or reproducing (or both) were sufficiently low in alternative 'marginal' habitats (Koenig and Pitelka 1981; Emlen 1982; Zack and Ligon 1985a). Numerous factors, including resource levels or predation risk could determine habitat quality (Brown 1987; Ford et al. 1988). (2) Variation in food supplies among breeding seasons, combined with age- or status-dependent skill or competitive ability, could make breeding during food shortages prohibitively difficult for some individuals, and favor their retention in a group (Orians et al. 1977; Brown 1978, 1987; Emlen 1982). (3) Stable resource levels, as might result from reduced seasonality, could contribute to a breeding delay by increasing the survival of established breeders (Brown 1978, 1987; Woolfenden and Fitzpatrick 1984; Ford et al. 1988). (4) A shortage of mates could prevent some individuals from breeding (Rowley 1965; Brown 1978; Emlen $1978,1982,1984)$. (5) Living in a group could be confer large direct or indirect fitness benefits (Brown 1980) not available to individuals dispersing to breed independently (Brown 1978, 1987; Emlen 1978, 1982; Stacey and Ligon 1987). Nondispersers could gain by increasing their group's reproductive performance (Rabenold 1984), or its ability to defend space (Craig 1984), to detect or deter predators (McGowan and Woolfenden 1989), or to capture prey (Bednarz 1988). Remaining in a group could also be the only way for individuals to gain access to essential localized resources (Stacey and Ligon 1987).

A powerful way to investigate ecological influences on cooperative breeding is to compare closely related populations in different environments (e.g., Trail 1980; Reyer 1980; Zack and Ligon $1985 \mathrm{~b}$ ). This paper reports on a study of interand intra-specific variation in social organization of Galápagos mockingbirds (Nesomimus spp.). This endemic genus is closely allied to mockingbirds (Mimus spp.) of mainland America and the Caribbean. The four allopatric species of Nesomimus differ in plumage and morphology (Swarth 1931; Abbott and Abbott 1978), in displays and song (Gulledge 1970; Bowman and Carter 1971), and in some foraging techniques (Bowman and Carter 1971; Curry and Anderson 1987). Galápagos mockingbirds are permanently territorial (Hatch 1966; Grant and Grant 1979). Most environments they inhabit are highly seasonal and are subject to large and unpredictable variation in climatic conditions among years (Grant and Boag 1980; Grant 1985). Cooperative breeding in $N$. parvulus has been the subject of long-term study on Genovesa (Grant and Grant 1979; Kinnaird and Grant 1982; Curry and Grant 1989a, b) but social organization in other populations has not been examined previously.

I investigated mockingbird social organization on four islands (Genovesa, Champion, Española, and San Cristóbal). To control partially for annual variation in climatic conditions, I collected data on all islands during a single year. My primary purpose was to seek correlations between social organization and ecological characteristics of the different sites. I also made the following general predictions. From hypothesis (1) above, I predicted that differences in the habitats available on the four islands would produce variation in social organization. Of the four islands, only San Cristóbal supports a broad range of habitats; I expected mockingbirds there to have more dispersal opportunities and to be less social than on the other islands. From hypothesis (2), I expected little variation in social organization among arid lowland sites, because such sites throughout the archipelago experience similar climatic conditions in each year (Grant and Boag 1980). Hypothesis (2) also predicted that birds in the seasonal and annually variable lowlands, where harsh conditions should favor an increase in delayed breeding, would be more social than those in the comparatively aseasonal highlands; hypothesis (3) made the opposite prediction. I expected, from hypothesis (4), that differences in adult sex ratio among the populations would affect group size by influencing the proportions of birds obtaining mates. Among the numerous possible predictions of hypothesis (5), I tested whether groups were larger on islands with greater risk from predators (Ford et al. 1988).

\section{Methods}

Study sites and periods of observation

The four islands included in the study differ in size, altitude, and diversity of vegetation zones (Table 1). Genovesa, Española, and Champion are low and relatively small; each supports only xero- 
Table 1. Characteristics of islands and mockingbirds (Nesomimus spp.) studied

\begin{tabular}{|c|c|c|c|c|c|c|c|c|}
\hline Island $^{\mathrm{a}}$ & \multicolumn{2}{|l|}{ Genovesa } & \multicolumn{2}{|l|}{ Champion } & \multicolumn{2}{|l|}{ Española } & \multicolumn{2}{|c|}{ San Cristóbal } \\
\hline Area $\left(\mathrm{km}^{2}\right)$ & \multicolumn{2}{|l|}{17.4} & \multicolumn{2}{|l|}{0.1} & \multicolumn{2}{|l|}{58.0} & \multicolumn{2}{|l|}{552.0} \\
\hline Altitude (m) & \multicolumn{2}{|l|}{76} & \multicolumn{2}{|l|}{46} & \multicolumn{2}{|l|}{198} & \multicolumn{2}{|l|}{715} \\
\hline Vegetation Zones & \multicolumn{2}{|c|}{ Littoral, Arid } & \multicolumn{2}{|c|}{ Littoral, Arid } & \multicolumn{2}{|c|}{ Littoral, Arid } & \multicolumn{2}{|c|}{$\begin{array}{l}\text { Littoral, Arid, } \\
\text { Transition, Scalesia, } \\
\text { Miconia, Fern/Sedge }\end{array}$} \\
\hline Mockingbird species ${ }^{b}$ & \multicolumn{2}{|l|}{ N. parvulus } & \multicolumn{2}{|c|}{ N. trifasciatus } & \multicolumn{2}{|c|}{$N$. macdonaldi } & \multicolumn{2}{|c|}{ N. melanotis } \\
\hline Sex & $\hat{\partial o}$ & QP & $\widehat{\partial o x}$ & OPQ & 30 & op & $\partial \hat{\partial}$ & oq \\
\hline Wing length $(\mathrm{mm})^{\mathrm{C}}$ & $118.0 \pm 0.2$ & $110.1 \pm 0.1$ & $125.9 \pm 0.5$ & $116.8 \pm 0.3$ & $125.0 \pm 0.2$ & $115.2 \pm 0.3$ & $114.5 \pm 0.5$ & $106.6 \pm 0.3$ \\
\hline Bill length $(\mathrm{mm})^{\mathrm{d}}$ & $20.3 \pm 0.1$ & $19.6 \pm 0.1$ & $20.4 \pm 0.2$ & $20.0 \pm 0.1$ & $24.1 \pm 0.1$ & $23.0 \pm 0.1$ & $17.6 \pm 0.1$ & $16.6 \pm 0.1$ \\
\hline Mass $(\mathrm{g})$ & $56.2 \pm 0.4$ & $51.2 \pm 0.3$ & $65.7 \pm 0.7$ & $59.8 \pm 0.5$ & $76.1 \pm 0.4$ & $64.8 \pm 0.6$ & $53.2 \pm 0.6$ & $48.0 \pm 0.7$ \\
\hline$n$ & 150 & 178 & 33 & 54 & 140 & 77 & 27 & 18 \\
\hline
\end{tabular}

a Island areas, altitudes, and zonation from Wiggins and Porter (1971); Scalesia, Miconia, and fern/sedge zones on San Cristóbal have been severely degraded following human settlement (Hamann 1984; see Table 2)

${ }^{b}$ Mean \pm SE shown for measurements of adult mockingbirds banded on each island

${ }^{c}$ Length of flattened wing; values used to distinguish males from females were 114, 120, 120, and 110 mm for Genovesa, Champion, Española, and San Cristóbal respectively

${ }^{d}$ Nares to tip

phytic vegetation. San Cristóbal is a larger high island, with more vegetational zones. The islands also differ in their suites of known or potential mockingbird predators. Short-eared owls (Asio flammeus), yellow-crowned night-herons ( $N y c t i-$ corax violacea), and lava herons (Butorides / striatus ] sundvalli) inhabit all four islands; snakes (Elaphus spp.) live on Champion, Española, and San Cristóbal; Galápagos hawks (Buteo galapagoensis) inhabit only Española; and barn owls (Tyto alba), introduced black rats (Rattus rattus) and feral cats are present only on San Cristóbal (Eckhardt 1972; Harris 1973; Hoeck 1984; Curry, pers. obs.).

Mockingbird populations were studied for 1 to 5 months between December, 1983, and May, 1984, at eight sites (Fig. 1). Data collected on Genovesa and Champion form part of longitudinal studies. P.R. Grant and coworkers studied N. parvulus on Genovesa between 1978 and 1980 and I studied the Genovesa population during the breeding season in each year, 1981-86; Grant and coworkers provided data from July-August of most years (see Curry and Grant 1989a for additional details). Grant banded all N. trifasciatus on Champion in August 1980. This permanently resident population was then observed during two brief visits (1-7 days) in each year, 1981-83, and for a total of 8 weeks between December, 1983, and May, 1984.

I collected data on Española and San Cristóbal only during the 1983-1984 breeding season. $N$. macdonaldi on Española was studied for five months at two coastal sites. Site E1 covered a small peninsula $1 \mathrm{~km}$ north of Punta Cevallos. Site E2 fell within the large seabird colony at Punta Cevallos. Mockingbirds were also studied at an inland

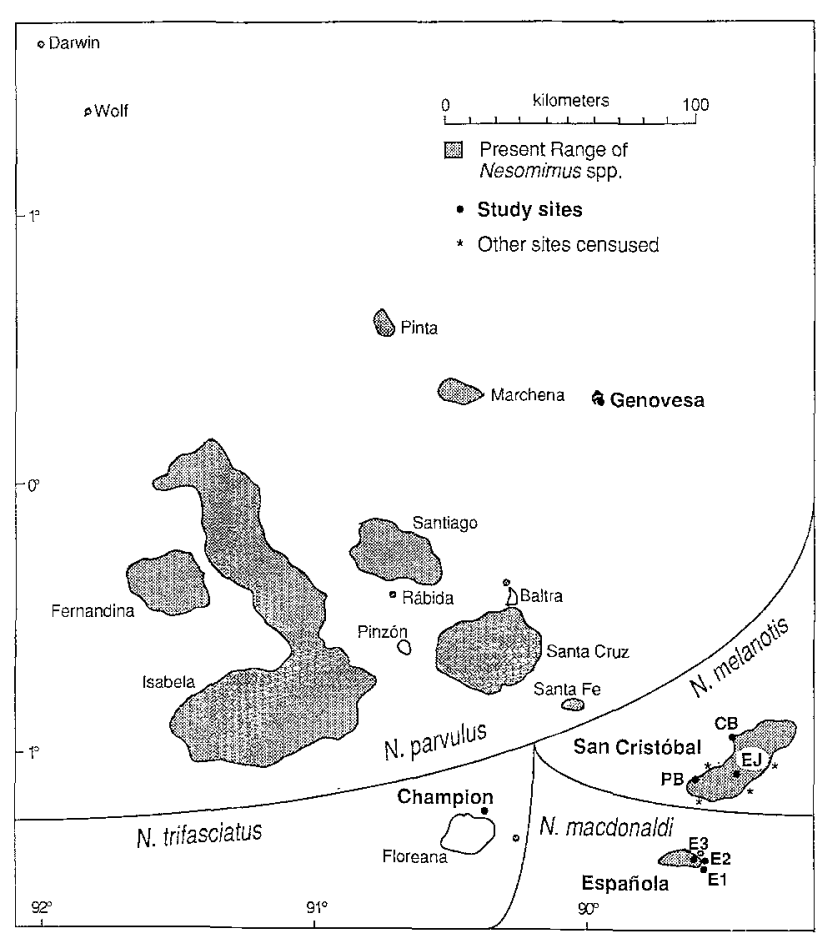

Fig. 1. Map of the Galápagos Archipelago showing distribution of the four species of mockingbirds (Nesomimus spp.) and locations of sites included in this study. Mockingbirds have been extirpated from Floreana and Baltra (Curry 1986) and are not known to have occurred on Pinzón 
site (E3), $3 \mathrm{~km}$ west of E1, for 1 week in February. On San Cristóbal, I studied $N$. melanotis at Playa Baquerizo (hereafter PB) for a total of three weeks between December and February, and at Cerro Brujo (CB) for six weeks in March and April; both $\mathrm{CB}$ and $\mathrm{PB}$ are arid coastal sites $(0-200 \mathrm{~m}$ elevation). I censused mockingbirds during brief (1 day) visits to four other coastal sites on San Cristóbal (Fig. 1). I studied mockingbirds in the highlands at $\mathrm{E} 1 \mathrm{Junco}$ (EJ; ca. $650 \mathrm{~m}$ elevation) for four weeks in February and March.

The assumption that climatic conditions are more benign (wetter) and less variable in the highlands than at low elevation is supported by longterm rainfall records (Grant and Boag 1980) and by recent data: on San Cristóbal, rainfall at Progreso ( $250 \mathrm{~m}$ elevation) totalled $774 \mathrm{~mm}$ in 1980 , $1851 \mathrm{~mm}$ in 1982, and $3976 \mathrm{~mm}$ in 1983 during an extraordinarily strong EL Niño-Southern Oscillation (ENSO) event; comparable values for the same years at the town of Wreck Bay, in the arid zone $2 \mathrm{~km}$ west of $\mathrm{PB}$, were $190 \mathrm{~mm}, 366 \mathrm{~mm}$, and $3409 \mathrm{~mm}$ (Robalino 1985).

\section{Data collection}

At all sites, mockingbirds were captured and marked with numbered aluminum leg bands and two or three plastic color bands. Sexes were determined from measurements of wing length (Grant and Grant 1979; Curry and Grant 1989a). In each population, males have longer wings than females (Swarth 1931); different criterion values for wing length were used for separating males from females on each island (Table 1). Sex classifications based on wing length were confirmed by observations of breeding behavior with few $(<1 \%)$ exceptions. Sex could not be determined for birds that had intermediate measurements and that did not breed.

Detailed maps of the study areas were drawn from aerial photographs and ground measurements. I calculated areas from computer-digitized tracings of the maps. Mockingbird densities reported here include only adult residents, classified as birds that were regular members of territorial groups (below) and a few non-territorial floaters $(1 \%$ of males and $4 \%$ of females on Genovesa; Curry and Grant 1989b). I calculated density for San Cristóbal only over the area actively defended by territorial groups, excluding areas used occasionally by mockingbirds in peripheral territories. My density comparisons are therefore conservative. On all islands, I considered individuals as adults after the attainment of adult plumage (at about 8 months of age).
Membership in territorial groups was determined from observations of dominance displays and territorial interactions. On all islands, dominant males elicited subordinate displays from other residents. All birds subordinate to a given a male and resident within his territory were defined as members of his group. Boundaries of group territories were mapped on the basis of movements of resident birds and locations of territorial border displays (Curry 1988b).

I attempted to monitor all breeding activity at each site. Mockingbirds on Genovesa and Champion nested in every year, 1980-1984, although fewer pairs than normal nested within in the Genovesa study area in 1984 (Curry and Grant 1989a and below). In 1984, breeding took place on Española in March and was studied only at E1 and E2. On San Cristóbal, mockingbirds nested in February at PB, in February and March at EJ, and in April at $\mathrm{CB}$. Behavior at nests with eggs or chicks was quantified during 1 -h watches every 1 to 3 days. I classified mockingbirds as helpers only if they fed nestlings or fledglings other than their own offspring.

\section{Results}

Spatial distribution of mockingbirds in relation to habitat availability

Lowland sites. The range of habitats present at lowland sites varied among the four islands (Table 2). On Genovesa, Champion, and Española, habitat diversity in the arid zone was low. The Genovesa study site, and nearly the entire island, was covered by uniform deciduous woodland dominated by the tree Bursera graveolens, with smaller areas of low scrub and littoral vegetation (mangroves and Cryptocarpus pyriformus; Fig. 2A; see photographs in Plage and Plage 1988: 132-134; Curry and Grant 1989 b). Vegetation on Champion, an eroded tuff cone, consisted mainly of large cacti (Opuntia megasperma) and low shrubs (Fig. 2B). On Española, habitat at E1 was a mixture of thorny scrub, dominated by Prosopis juliflora, and low littoral vegetation, fringed by an extensive intertidal zone (Fig. 2C). Habitats at E2 were similar, but with a broader strip of littoral vegetation (Fig. 2D). Vegetation at E3, which covered 7.5 ha in Española's interior (not illustrated), was like the taller scrub of the coastal sites, but with scattered Bursera trees and cacti (O. megasperma).

Habitats in the arid zone of San Cristóbal were more diverse (Table 2). The $\mathrm{CB}$ study area included a central area of woodland, dominated by 
Table 2. Distribution of habitats and their occupancy by mockingbirds at study areas on four islands. Each habitat is categorized as defended by territorial mockingbirds $(\mathrm{T})$, present but not occupied by territorial mockingbirds (NO), or not present $(-)$

\begin{tabular}{|c|c|c|c|c|}
\hline Habitat & Genovesa & Champion & Española & San Cristóbal \\
\hline \multicolumn{5}{|l|}{$\begin{array}{l}\text { Arid lowlands (Genovesa, Champion, and Española; } \\
C B \text { and } P B \text { sites on San Cristóbal) }\end{array}$} \\
\hline $\begin{array}{l}\text { Scrub woodland: low, open canopy of Bursera graveolens; } \\
\text { scattered cacti (Opuntia spp.); shrubby understory } \\
\text { (principally Cordia lutea and Croton scouleri) }\end{array}$ & $\mathrm{T}$ & - & $\mathrm{T}$ & NO \\
\hline $\begin{array}{l}\text { Cactus scrub: abundant arborescent Opuntia; } \\
\text { Croton and Cordia understory }\end{array}$ & - & $\mathrm{T}$ & - & NO \\
\hline $\begin{array}{l}\text { Piscidia woodland: canopy of Piscidia carthaginensis } \\
\text { and Bursera, dense understory }\end{array}$ & - & - & - & $\mathrm{T}$ \\
\hline Littoral: halophilic shrubs, mangroves, sandy beaches, rocky shore & $\mathrm{T}$ & $\mathrm{T}$ & $\mathrm{T}$ & $\mathrm{T}$ \\
\hline Barren rocky slopes, lava fields & $\mathrm{T}^{*}$ & - & - & NO \\
\hline \multicolumn{5}{|l|}{ Highlands (El Junco site on San Cristóbal only) } \\
\hline $\begin{array}{l}\text { Scrubby guava forest: low, closed canopy of introduced guava } \\
\text { (Psidium guajava) }\end{array}$ & - & - & - & $\mathrm{T}$ \\
\hline Pastures: small grassy fields with scattered Psidium and Citrus spp. & - & - & - & $\mathrm{T}$ \\
\hline Pampas: large open areas of grasses and sedges & - & - & - & NO \\
\hline $\begin{array}{l}\text { Dense moist forest: high canopy of native trees, Psidium, } \\
\text { and Citrus spp. }\end{array}$ & - & - & $-\dot{x}$ & NO \\
\hline
\end{tabular}

* A narrow strip of barren, unvegetated lava along the outer coast of Genovesa, outside the study area, appeared to be used by birds holding territories in adjacent scrub habitat

the tree Piscidia carthaginensis, within and beneath the crater of Cerro Brujo, a solitary tuff cone. Peripheral habitats included barren hillsides, mangroves and salt lagoons, a large unvegetated lava field, and an area of Bursera-dominated woodland extending several $\mathrm{km}$ northeast (Fig. 2E). The PB site (not illustrated) included approximately 15 ha of woodland, dominated by Piscidia and Bursera, surrounded by more open scrub with scattered Bursera trees.

On Genovesa, Champion and Española, but not on San Cristóbal, territorial mockingbirds occupied all available habitat in the lowlands (Table 2). Contiguous, continuously-defended territories filled the Genovesa study area in 1984 (Fig. 2A) and during all other periods of study, except for small areas left vacant for 1-2 months during an epizootic in 1983 (Curry and Grant 1989a). Territories also filled all vegetated habitat on Genovesa outside of the study area. Champion was similarly occupied completely by mockingbird territories during all periods of study, including 1984 (Fig. 2B). In coastal sites E1 and E2 on Española, mockingbird territories filled the vegetated areas, and their borders extended into the intertidal zone (Figs. 2C and 2D). The configuration of territories at E1 was similar in 1974 (S. Groves, pers. comm.).

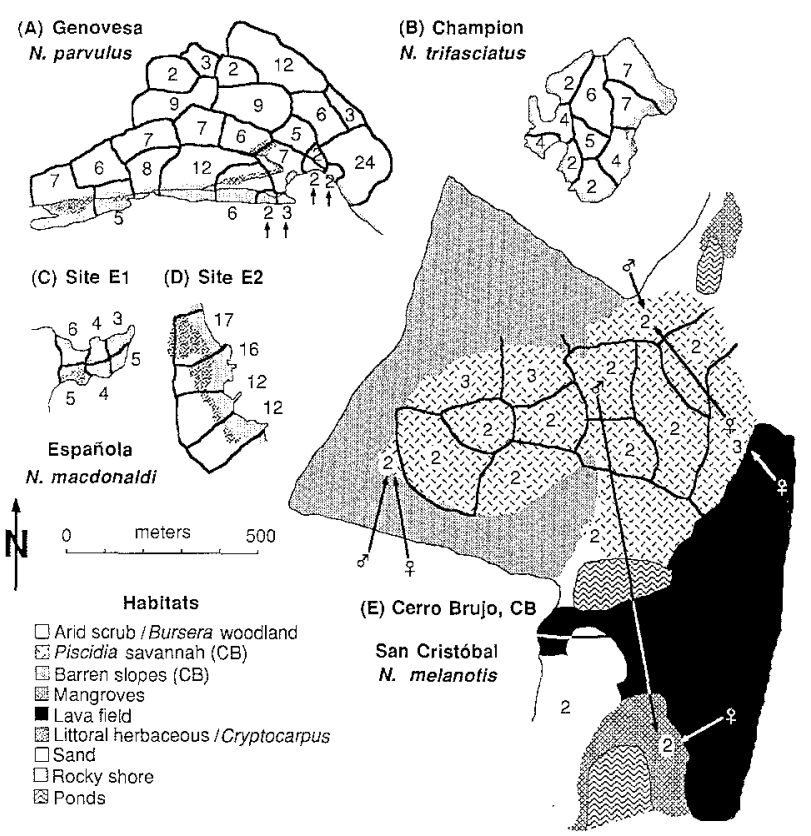

Fig. 2. Distribution of territorial mockingbirds on four islands. Maps, drawn to common scale, show habitat variation and territorial boundaries (heavy lines) defended during breeding in March-April, 1984, at five sites; patterns at two additional sites (PB and EJ on San Cristóbal) are described in the text. Numerals indicate the number of adults in each territorial group. On Genovesa and Española, additional groups occupied areas adjacent to territories shown, but some borders on San Cristóbal were indefinite where groups had no neighbors; the map of Champion shows the entire islet. Arrows denote newly established territories (A) or movements of individuals resulting in establishment of new territories (E; see text) 
Two groups, of eight and 10 birds respectively, occupied site E3 in Española's interior. Their territories were bordered by other groups on all sides. On all islands, mockingbirds remained in their territories for all breeding and most foraging activity, except that birds holding territories up to $2 \mathrm{~km}$ from the shore on both Genovesa and Española occasionally visited coastal areas to forage in the intertidal and littoral zones. At both E1 and E2 on Española, visitors (and the local territorial residents) fed on invertebrates and on blood from seabirds, iguanas, and sealions (Curry and Anderson 1987).

On San Cristóbal, unlike the other islands, some of the habitas at each lowland site were not occupied by territorial mockingbirds (Table 2). At $\mathrm{CB}$, mockingbirds held territories in Piscidia-dominated woodland and in mangroves, but not in other adjacent habitats (Fig. 2E). Occasionally I saw birds from nearby territories, along with several unmarked birds of unknown origin, moving unmolested through undefended habitat peripheral to the Piscidia woodland; one unpaired male, for example, often sang in the Bursera scrub, up to $200 \mathrm{~m}$ away from his group's nest in the woodland. At PB, four territorial groups actively defended boundaries against each other in the dense central woodland. Birds from these groups also wandered sometimes into surrounding habitat, where they had no territorial neighbors.

Territorial mockingbirds occupied few or none of the available habitats at the other locations I visited in San Cirstóbal's arid zone. I found five solitary singers and two probable pairs along coastline $5 \mathrm{~km}$ south and $8 \mathrm{~km}$ north of $\mathrm{CB}$, all in isolated mangrove stands. Habitat along the rest of this shoreline consisted of sparse scrub on recent lava flows. I found only a few solitary mockingbirds within $2 \mathrm{~km}$ on either side of the central cluster of territories at PB. I observed no territorial mockingbirds in Bursera-dominated scrub at three other coastal sites (Bahía Rosa Blanca, Puerto Chino, and Isla Lobos) or in an Opuntia forest near Bahía Agua Dulce.

Highlands. Vegetation at the 40-ha EJ site on San Cristóbal (not illustrated) consisted primarily of a low forest of introduced guava (Psidium guajava) up to $4 \mathrm{~m}$ tall, with a few small pastures (up to 2 ha) and temporary ponds (Table 2 ). The site was occupied by eight mockingbird territories. Three of these territories, containing two $(n=2)$ or three birds $(n=1)$, were bordered on all sides by neighboring territories. The five peripheral territories, which were occupied by an unpaired male $(n=1)$, a simple pair $(n=2)$, and a trio $(n=2)$, extended into unoccupied habitat. I found no territorial residents in open grazed grassland (pampas) on the tops of the island's highest hills, or in dense forest at lower elevation.

\section{Establishment of new territories}

During the brief period of study at $\mathrm{CB}$, mockingbirds established three new territories adjacent to the main cluster of territories (Fig. 2E). In each case, a male settled in a previously unoccupied area and began singing, shortly after mockingbirds in the rest of the CB study area began nesting. The origin of two of the males was unknown, but the third was a subordinate member of a trio (see below) before moving about $400 \mathrm{~m}$. Within a week after settling, all three males were joined by females. Two of these females came from outside the central cluster of territories. The third came from a nearby group, where she was replaced by another female of unknown origin. Two of the newly-formed pairs subsequently nested.

Mockingbirds almost never established new territories in this way on the other three islands, because unoccupied habitat usually was not available. Four pairs on Genovesa filled vacancies in the center of the study area soon after previous territorial residents died from disease in 1983. Four other groups of yearlings on Genovesa established new, small territories in 1984 (Fig. 2A) in habitat that was previously included within other larger territories. Two such territories in the littoral zone contained no vegetation and were later reincorporated into adjacent larger territories. Between 1980 and 1984, only one new territory was established on Champion, in an area previously defended by an adjacent group. All other territorial changes on both Genovesa and Champion resulted from transfers of birds among groups and gradual shifts of established boundaries. On Española, no change in territory occupancy occurred during five months of study at either E1 or E2.

\section{Group territoriality and cooperative breeding}

Group size. Average group size was highest on Española and intermediate on Genovesa and Champion; groups on San Cristóbal were significantly smaller (Fig. 3 ; Kruskal-Wallis $H=32.9,3$ d.f., $P<0.001)$. Mean group size did not vary among sites on San Cristóbal, and I found no groups larger than three birds. Group size at E1 did not differ significantly from Genovesa or Champion, but groups at E2 were larger (Mann 
Table 3. Geographic variation in group territoriality, adult sex ratio, and population density

\begin{tabular}{|c|c|c|c|c|}
\hline \multirow{2}{*}{$\begin{array}{l}\text { Island and study } \\
\text { site or year }\end{array}$} & \multicolumn{2}{|c|}{ Relative frequency of groups of $\geq 3$ birds } & \multirow{2}{*}{$\begin{array}{l}\text { Adult sex ratio } \\
(\% \text { males })^{a}\end{array}$} & \multirow{2}{*}{$\begin{array}{l}\text { Density } \\
\text { (adults/ha) }^{\mathrm{b}}\end{array}$} \\
\hline & $\%$ of groups $(n)$ & $\%$ of birds $(n)$ & & \\
\hline \multicolumn{5}{|l|}{ Genovesa } \\
\hline $\begin{array}{l}1984 \\
1980-1984^{b}\end{array}$ & $\begin{array}{rr}76 \% & (25) \\
74 \% & (149)\end{array}$ & $\begin{array}{rr}93 \% & (90) \\
88 \% & (654)\end{array}$ & $\begin{array}{l}42.3 \% \\
53.5 \pm 7.5 \%\end{array}$ & $\begin{array}{l}4.4 \\
4.2 \pm 0.9\end{array}$ \\
\hline \multicolumn{5}{|l|}{ Champion } \\
\hline $\begin{array}{l}1984 \\
1980-1984^{b}\end{array}$ & $\begin{array}{ll}70 \% & (10) \\
77 \% & (52)\end{array}$ & $\begin{array}{lr}86 \% & (43) \\
87 \% & (180)\end{array}$ & $\begin{array}{l}48.6 \% \\
46.0 \pm 6.4 \%\end{array}$ & $\begin{array}{l}4.9 \\
4.3 \pm 0.6\end{array}$ \\
\hline \multicolumn{5}{|l|}{ Española (1984) } \\
\hline $\begin{array}{l}\text { All sites } \\
\text { E1 } \\
\text { E2 } \\
\text { E3 }\end{array}$ & $\begin{array}{rr}100 \% & (12) \\
100 \% & (6) \\
100 \% & (4) \\
100 \% & (2)\end{array}$ & $\begin{array}{rr}100 \% & (102) \\
100 \% & (27) \\
100 \% & (57) \\
100 \% & (18)\end{array}$ & $\begin{array}{l}63.5 \% \\
55.2 \% \\
63.3 \% \\
75.0 \%\end{array}$ & $\begin{array}{l}9.2 \pm 6.8 \\
16.1 \\
9.2 \\
2.4\end{array}$ \\
\hline \multicolumn{5}{|c|}{ San Cristóbal (1984) } \\
\hline $\begin{array}{l}\text { All sites }^{c} \\
\text { CB } \\
\text { PB } \\
\text { EJ }\end{array}$ & $\begin{array}{rr}25 \% & (28) \\
19 \% & (16) \\
25 \% & (4) \\
38 \% & (8)\end{array}$ & $\begin{array}{rr}34 \% & (62) \\
26 \% & (35) \\
33 \% & (9) \\
50 \% & (18)\end{array}$ & $\begin{array}{l}56.5 \% \\
54.3 \% \\
55.6 \% \\
61.1 \%\end{array}$ & $\begin{array}{l}0.6 \pm 0.1 \\
0.7 \\
0.6 \\
0.5\end{array}$ \\
\hline
\end{tabular}

${ }^{\text {a }}$ Percentage of residents of known sex

${ }^{\mathrm{b}}$ Mean values shown for sex ratio and density, expressed as $\bar{x} \pm \mathrm{SD}, n=5$ years

c Values are for all residents studied on each island combined, except density expressed as $\bar{x} \pm \mathrm{SD}, n=3$ sites

Whitney $U$-tests, $P<0.01)$. The percentage of groups larger than two similarly varied among the islands (Table $3 ; \chi^{2}=21.73,3 d f ., P<0.001$, using data from 1984), ranging from $25 \%$ on San Cristóbal to $100 \%$ on Española. The proportion of individuals living in groups larger than two was correspondingly lowest (34\%) on San Cristóbal (Table 3). Neither proportion varied significantly among the three San Cristobal sites. Fewer birds lived in groups larger than two on both Genovesa $\left(\chi^{2}=6.01,1 d . f ., P<0.05\right)$ and Champion $\left(\chi^{2}=\right.$ 11.54, 1 d.f., $P<0.005)$ than on Española, where all mockingbirds belonged to large groups.

Temporal variation in group size on both Genovesa and Champion was small in relation to the magnitude of the differences in group size among the islands, even though conditions during 1983 El Niño may have influenced the size of groups observed in 1984. Groups on Genovesa were significantly larger in 1984 on average than in previous years (range of means, 3.2-4.4 birds, 1980-1983), both because many birds born during 1983 were recruited and because a few large groups of yearlings (12-24 birds) formed through fusion following the death of older, dominant individuals (Curry 1988b). Group size on Champion varied less (range 2.6-3.5, 1980-1983), but increased in 1984 for the same reasons as on Genovesa. Group size in 1984 at E1 on Española had increased only slightly since 1974 when three groups averaged $5.0 \pm 1.0 \mathrm{sD}$ birds (S. Groves, personal communication).

On each of the four islands, group size correlated positively with territory size, but territory size varied among islands (Kruskal-Wallis $H=33.2$, $3 d . f ., P<0.005)$ inversely with differences in group

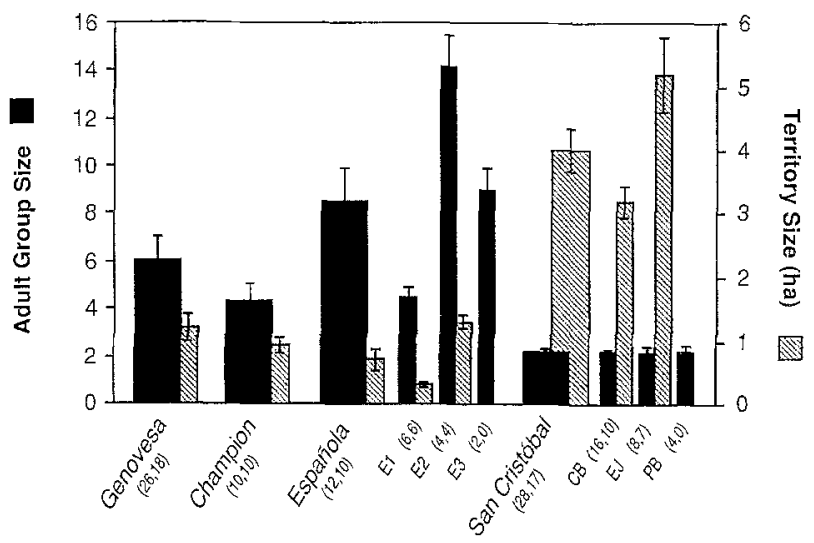

Fig. 3. Geographic variation in group size and territory size. Wide black and hatched bars denote mean group size $( \pm \mathrm{SE})$ and territory size $( \pm \mathrm{SE})$ respectively on each the four islands (data from 1984; sites on Española and San Cristóbal combined). Narrow bars show values for the different Española and San Cristóbal study sites individually. Numbers of groups and territories measured are indicated within parentheses 
size (Fig. 3). Territories on San Cristóbal were significantly larger than on each of the other islands. Territories were also larger at EJ (5.2 ha $\pm 0.6 \mathrm{SE}$, $n=7)$ than at CB $(3.2 \pm 0.1$ ha, $n=10$; Mann Whitney $U$-test, $P<0.05$ ), though average group size at these sites was the same.

Groups on Genovesa are maintained through delayed dispersal: most yearlings (74\% of males, $56 \%$ of females) remain in their natal territory, and most adults ( $96 \%$ of males, $77 \%$ of females) stay in the same group between years (Curry and Grant 1989b). Movement patterns on Champion were similar (R.L. Curry and P.R. Grant, in preparation). Two males resident at site E1 in 1984 remained in the territories where they were banded as adults in 1974 by S. Groves (personal communication), suggesting that dispersal is likewise reduced on Española. No information about group formation is available from San Cristobal. On all of the islands, one male was dominant over all other males in each group. Dominance among males on Genovesa is determined by relative age; males also dominate females, and higher ranking birds most often breed (Curry 1988 b). All males that bred on Champion in $1984(n=10)$ were also the highest ranking members of their groups. Each of the two old males ( $\geq 11$ years of age) at E1 were the dominant birds in their groups, and both bred in 1984. The breeding structure of groups necessarily differed on the four islands because of variation in group size. Two females bred (plural breeding; Brown 1978) in one $(14 \%)$ of seven groups nesting on Genovesa in 1984, as they did in $43 \%$ of groups $(n=122)$ in 1980-83 (Curry 1988 b). There were no plural groups on Champion in 1984, but two such groups occurred there in 1983. On both islands, groups maintained stable territorial borders throughout the year; even when multiple pairs began breeding, groups did not split up. Although no more than one pair bred in 1984 in any territory on Española, additional pairs in each of the large groups at E2 did construct nests, suggesting that plural breeding occurs in some years. No plural breeding occurred on San Cristóbal because all groups larger than two consisted of a mated pair and an extra, subordinate male. As on Genovesa (Curry 1988b), dominant males closely guarded their mates and appeared to prevent subordinate males from copulating.

Helping behavior. Helping occurs regularly on Genovesa. Between 1980 and 1984, 41\% of nests with chicks $(n=254)$ were attended by one or more helpers, all of which were members of the same social group as the breeders; 1984 was average in this respect as helpers attended two (40\%) of five nests containing hatchlings. The majority of helpers on Genovesa were young nonbreeding adult males, $39 \%$ of which helped when they had an opportunity to do so; most helpers were still in their natal groups, where they preferentially helped raise closely related nestlings (Curry 1988a). On Champion, helpers fed young in seven $(78 \%)$ of nine nests with hatchlings observed between 1981 and 1984. The helpers included six adult males, two adult females, and seven immature birds. Three helpers fed known siblings and one fed nestlings that were at least half siblings; none fed nestlings that were known to be less closely related. On Española, S. Groves (personal communication) saw three adult males and one adult female feed young in a nest at E1 in 1974. In 1984, however, only one nest in each of the two coastal study areas reached the nestling stage, and the parents made all feeding visits observed at these nests $(n=46$ and 33 visits during 600 and $540 \mathrm{~min}$ of observation respectively), though nonbreeders that could have helped were present (one male in one group, and seven males and three females in the other). The frequency of helping behavior on Española therefore remains uncertain.

No helping has yet been observed at nests on San Cristóbal (see Venables 1940) but observations of marked birds during the nestling phase are still lacking: none of the nests I studied on San Cristóbal in $1984(n=13)$ contained hatchlings (see below). At both $\mathrm{CB}$ or $\mathrm{EJ}$, extra males in trios did not participate either in building the breeding pair's nest or in defending it during incubation. Instead, each subordinate male usually sang or foraged elsewhere in its group's territory. Even if every extra male in a trio on San Cristóbal were to help, the incidence of helping (roughly $25 \%$ of nests) would be lower than on Genovesa or Champion. On Genovesa, however, many nonbreeders do not act as helpers (Curry 1988a). Assuming the same is true on San Cristóbal, helping probably occurs there rarely, if at all.

\section{Population structure}

Adult sex ratio. Adult sex ratio varied geographically and temporally among the eight populations (Table 3). On Genovesa, males outnumbered females in each year prior to 1983 , whereas females predominated in 1984, as a result of differential mortality (Curry and Grant 1989a). On Champion, this pattern was reversed: females predominanted except in 1983, when males were in excess. 
Therefore, the sex ratio recorded in 1984 was close to the five-year average on Champion but not on Genovesa. Males outnumbered females at all sites on Española and San Cristóbal.

Variation in sex ratio among years and among the islands did not correlate with variation in group structure. Despite opposite trends in adult sex ratio, groups on Champion and Genovesa were similar in size throughout the study and they regularly contained multiple adults of each sex. Large groups on Española contained up to eight individuals of each sex. These results would not be expected if lack of mates caused delays in breeding or dispersal. Local availability of mates could have a greater influence on San Cristóbal, where all auxiliary group members were unpaired males. The ability of some males to obtain mates after establishing new territories suggests, however, that some additional females not included in sex ratio calculations existed as floaters in habitats not occupied by territorial mockingbirds on San Cristóbal.

Density. Density varied little among the three San Cristóbal study areas, but was much lower at all three than on any of the other islands (Table 3 ). The range of density among the three sites on Española was broad and encompassed the densities measured on Genovesa and Champion. Density was highest overall at the coastal Española site $\mathrm{E} 1$, where the value was more than 30 times greater than at EJ - even though densities measured on San Cristóbal represent maximum estimates, while values from Española are minimal (see Methods).

Densities measured in 1984 on Genovesa and Champion were only slightly higher than the averages over the period 1980-1984 (Table 3). Almost half of the adults on Genovesa died in an epizootic (apparently of poxvirus) during the 1982-83 ENSO, but these losses were more than offset by high production young in 1983 by the surviving breeders (Curry and Grant 1989a). Natality in 1983 similarly outstripped mortality from disease on Champion.

\section{Climatic conditions and social organization}

The 1982-83 ENSO brought heavy rain to the entire archipelago (Grant 1984; Robalino 1985). As a result, mockingbird breeding in 1983 was prolonged on all four study islands, lasting up to nine months on Genovesa (Curry and Grant 1989a). The epizootic that increased mortality on Genovesa also affected mockingbirds during 1983 on the three other islands studied in 1984 (Curry
1985). Therefore, the exceptional pattern of habitat use, group size, and density on San Cristóbal probably cannot be attributed, directly or indirectly, to geographic variation in climatic conditions, and their effects on mockingbird populations, prior to 1984.

Climatic conditions during the study also fail to account for inter-island variation in social organization. All lowland sites experienced relatively dry conditions, and poor conditions for breeding, in 1984. Genovesa received $69 \mathrm{~mm}$ (compared to an annual average of $142 \mathrm{~mm}$ for the period 1978 1982), while approximately $65 \mathrm{~mm}$ fell on Champion, $155 \mathrm{~mm}$ at $\mathrm{E} 1$, and $58 \mathrm{~mm}$ at $\mathrm{CB}$. Only eight pairs nested in the Genovesa study area in 1984, and no pairs produced surviving fledglings, in an area where up to 50 pairs normally nest (Curry \& Grant 1989a). On Española, three clutches and two fledglings were produced in the 10 territories at E1 and E2 in 1984; as on Genovesa, other residents built additional nests but did not produce eggs. On San Cristóbal, one pair at EJ was accompanied in March by a fledgling born before the study began. Five of seven pairs there later built nests and two produced clutches, but none was successful. At CB, 13 of 16 pairs built nests and 11 produced eggs, but none had produced hatchlings by the end of the study (when three nests with eggs remained). Breeding on Champion in 1984 was more widespread: 11 nests were produced in 10 territories, and eight young were fledged. These data suggest that conditions for breeding were no better on San Cristóbal in 1984 than elsewhere, and that climatic differences did not cause the exceptionally small groups on that island.

Galápagos mockingbirds in the highlands also nest following periods of rainfall (Venables 1940; this study). As expected, more rain ( $\geq 300 \mathrm{~mm}$ ) fell at EJ in February and March, 1984, than at any of the lowland study sites. This information, though indirect, is consistent with the assumption that conditions were more favorable for breeding at $\mathrm{EJ}$ than at $\mathrm{CB}$ or PB. Group size and patterns of territory occupancy were nonetheless essentially identical at these three San Cristóbal locations.

\section{Discussion}

The results of this study demonstrate that important features of social organization vary among populations and species of Galápagos mockingbirds. In all respects, Nesomimus melanotis on San Cristóbal is less social than its congeners. Comparable levels of variation in social structure among closely related populations have been docu- 
mented for several other genera (reviewed by Emlen and Vehrencamp 1983; Brown 1987; Stacey and Koenig 1989). In some (e.g., Lanius, Acanthiza), differences have been detected only between cooperatively breeding species and less social congeners. In other genera (e.g., Aphelocoma, Campylorhynchus, Melanerpes, Cyanocorax) variation exists, as in Nesomimus, both between species and between conspecific populations.

The occurrence of group-territorial cooperative breeding on Genovesa, Champion, and Española, and its absence or reduced frequency on San $\mathrm{Cr}$ istóbal, suggests that mockingbirds on the latter island are subject to some exceptional ecological factor or factors. One candidate is the broader range of habitats on San Cristóbal. Because all habitats on Genovesa, Champion, and Española support permanent mockingbird territories, young mockingbirds on these islands must remain in their natal territories, join other groups, compete for territories in space that is already occupied, or become floaters. The rarity on Genovesa and Champion of newly formed territories and of floaters ( $<2 \%$ of residents on Genovesa; Curry and Grant 1989 b) indicates the difficulty of the last two alternatives. Either of the other options causes groups to be maintained. San Cristóbal differs because it supports a wide range of habitats, not all of which are permanently occupied by territorial mockingbirds. The availability of varied habitats could favor dispersal in either of two ways. First, birds may leave their natal areas to live as nonbreeders in unoccupied habitat, while waiting for vacancies in high-quality territories. Movements of this kind have been proposed to account for the lack of cooperative breeding in Santa Cruz Island scrub jays (Atwood 1980) and Texas green jays (Gayou 1986). Second, some birds may leave preferred habitat to attempt breeding in other available habitat. Such dispersal might be favored, over remaining as a non-breeder in the natal territory, as long as birds breeding in suboptimal habitat do not suffer prohibitively low survival or reproductive success (Emlen 1982; Zack and Ligon 1985b; Fitzpatrick and Woolfenden 1986). My observations of birds at $\mathrm{CB}$ establishing new territories in vacant areas at the periphery of preferred habitat, and of scattered non-territorial birds living in other habitats, suggest that both mechanisms may operate on San Cristóbal. Either would result in reduced average group size and decreased frequency of helping. Results from the Galápagos are consistent, therefore, with the hypothesis that birds are forced to remain in groups where there is a sharp gradient in quality between preferred breeding habitat and other 'marginal' habitat (Koenig and Pitelka 1981): unlike San Cristóbal, the only unoccupied habitat available to dispersing mockingbirds on Genovesa, Champion, and Española is the Pacific Ocean.

Although the correlation between habitat availability and mockingbird social organization is consistent with the habitat constraints hypothesis, two other factors - predation and food supply - could alternatively account for the reduction in sociality on San Cristóbal, through their effects on demography. Mockingbirds on San Cristóbal must contend with two introduced predators, black rats (Rattus rattus) and cats, that do not occur on any of the other islands I studied (see Methods). Introduced rats have been implicated in the decline or extinction of many island birds (Atkinson 1985), including $N$. trifasciatus on Floreana (Curry 1986). San Cristóbal mockingbirds seem to suffer high rates of nest failure as a result of predation by rats: I found evidence linking rats to losses of 8 $(62 \%)$ of 13 mockingbird clutches at CB. Venables (1940) and H. Vargas (unpublished report) also blamed black rats for high rates of nest predation on San Cristóbal and Santa Cruz respectively. Cats probably pose a smaller risk. Mockingbirds mobbed, but seemed capable of avoiding, feral cats in all three San Cristóbal study areas; no adult resident disappeared during the 6 weeks of study at CB. Nestlings and fledglings undoubtedly are more vulnerable, but cats appear to concentrate on other prey. I found bird remains in only $8 \%$ of 136 cat scats on San Cristóbal, most of which contained remains of rats, mice, lizards, and arthropods. The number of mockingbirds killed by cats is unknown, but most of the bird remains were of the more abundant finches (Geospiza and $\mathrm{Ca}$ marhynchus spp.). If predation on San Cristóbal reduces mockingbird survival, or lowers reproductive success, or both, territories will become vacant more often in relation to the number of competing individuals than on the other islands. San Cristóbal birds consequently may have more frequent opportunities to disperse, resulting in a reduction in average group size. Although predation has not been confirmed as the cause, low juvenile survival has been associated with reduced group size, and an increase in dispersal distance, in at least one other cooperative breeder (Austad and Rabenold 1986).

My results are inconsistent, on the other hand, with the hypothesis that groups are maintained because of high risk of predation (Ford et al. 1988). This hypothesis would predict larger, rather than smaller, groups on San Cristóbal because it supports more potential predators. Three other lines 
of evidence argue against predation as a cause of group formation: Galápagos mockingbirds do not perform coordinated sentinel behavior, helpers do not influence rates of predation on nests (Curry 1987 and in preparation), and losses to predators appear to be lower than in some other cooperative breeders (Curry and Grant 1989a). It is nevertheless possible that hawks or owls present a greater threat to mockingbirds on islands other than San Cristóbal because, for example, of differences in habitat structure or mockingbird behavior (Ford et al. 1988). Additional data are needed to test whether demography varies among the islands as a result of predation. The relative importance of introduced predators, as opposed to habitat availability, could also be investigated further with data from another island (e.g., Pinta) having a range of habitats comparable to those on San Cristóbal, but lacking introduced predators.

Differences in resources among the islands could alternatively give rise to variation in social organization. If food supplies are more limited on San Cristóbal, mockingbird survival or fecundity may be lower than elsewhere. Again, such demographic shifts could permit more frequent dispersal into territorial vacancies and secondarily cause reduced group size. I did not collect quantitative information on food supplies in this study, but the larger territories held by mockingbirds on San Cristóbal (Fig. 2) are consistent with the hypothesis of lower food density (for a parallel example see Austad and Rabenold 1985, 1986). San Cristóbal mockingbirds also have shorter bills (Table 1), and they forage more arboreally (R.L. Curry, unpublished data) and less opportunistically than their congeners (Curry and Anderson 1987). These morphological and behavioral differences may magnify variation in food supplies. Variation in food availability and, correspondingly, demography could similarly explain why groups were larger and population densities higher at coastal sites on Española, where mockingbirds eat foods such as blood, carrion, marine invertebrates, and seabird eggs (Curry and Anderson 1987), than in that island's interior. Movements of birds among the sites, however, could also cause this pattern; neither alternative can be excluded without data on survival, reproduction, and dispersal.

All of the preceding mechanisms are consistent with the argument that reduced availability of preferred habitat, in relation to the number of competitors for territories, can constrain dispersal and breeding and cause cooperatively breeding groups to persist. The comparative results do not support the alternative hypotheses. Geographic variation in mockingbird social organization correlates poorly with differences in climatic conditions that would influence the costs of independent breeding (Orians et al. 1977; Emlen 1982). Social structure varied more among populations in lowland locations, which experience similar climatic conditions simultaneously throughout the archipelago (Grant and Boag 1980), than would have been expected under this hypothesis. Social organization would also be expected to vary among climatically different locations, but on San Cristóbal it did not. Consistency in the size of territorial groups on Genovesa and Champion, through both extremely wet and dry years, further indicates that prevailing climatic conditions do not have a predominant influence on mockingbird grouping patterns. Dispersal, breeding, and, consequently, the maintenance of social groups in Galápagos mockingbirds therefore appear to be influenced more by habitat availability in relation to population density than by variation in resources among breeding seasons (see also Curry and Grant 1989a). This conclusion suggests that the dichotomy, proposed by Emlen (1982; Emlen and Vehrencamp 1983), between habitat constraints in stable environments and climatic constraints in fluctuating environments is less important than the difference between territorial and colonial species (Brown 1987); in the latter, prevailing climatic conditions are more likely to have direct effects on resources needed for breeding (Reyer 1980; Emlen 1982). Climatic conditions can still have important secondary influences on the behavior of territorial species: in relatively dry years on Genovesa, interference by dominant birds in plural groups reduces the breeding success of subordinate pairs, whereas conflict within groups is reduced in wet years (Curry 1988 b).

There is also little evidence from this study to support the associated hypothesis that groups persist because young birds lack sufficient skill to breed independently (Brown 1978; 1987). Mockingbirds do not delay breeding as long as do many other cooperative breeders: yearlings on Genovesa regularly breed, and are often successful (Curry and Grant 1989a). The exceptionally small groups on San Cristóbal therefore could not be caused by a shorter breeding delay than on the other islands. Furthermore, fewer birds on Champion breed in their first year (Curry and Grant 1989b and in preparation) than on Genovesa, yet groups there average slightly smaller. Yearling males on Genovesa are rarely able to hold independent territories, however, breeding instead as subordinates (Curry and Grant 1989a). Skills acquired with age therefore may influence both dominance status 
and the reproductive tactics used by different age classes.

Geographic variation in mockingbird social organization correlates poorly with mate availability. Like climatic variation, however, mate availability does have a secondary influence on behavior within groups on Genovesa: variation in the sex ratio determines the proportion of birds that can mate and breed within each group (Curry 1988 b), which indirectly affects the frequency of helping behavior (Curry and Grant 1989a). Even if mate shortage cannot account for the existence of large mockingbird groups, however, the relative scarcity of females could explain why all auxiliary birds in groups on San Cristóbal were males - and why some of these males were able to breed elsewhere once additional females arrived, apparently from other areas of the island.

The comparative results of this study do not provide a direct test of the hypothesis that cooperative breeding arises when philopatric individuals gain a benefit over early dispersers, independent of habitat availability (Stacey and Ligon 1987). There is, however, no evidence of any large group benefit or critical resource that would confer a large advantage to philopatric mockingbirds. Mockingbirds do not engage in anti-predator behavior (see above) and they do not forage cooperatively. Small groups can exist side by side with larger groups (Fig. 2), indicating that extra members are not essential for territorial defence. Helpers on Genovesa also receive neither direct or indirect benefits large enough to inhibit independent breeding if mates and habitat are available (Kinnaird and Grant 1982; Curry 1987; Curry and Grant 1989a). The mockingbirds do not depend on any localized, limiting resource within acceptable habitat, and they do not create facilities (e.g., for storing food or roosting) that would magnify variation in territory quality.

If the physical limits of suitable habitat on small islands give rise to mockingbird territorial groups, are other Galápagos landbirds similarly affected? In general, the answer is no. The only other resident bird that is a frequent cooperative breeder is the endemic hawk. Galápagos hawks live in monogamous pairs or in polygyandrous groups whose territories fill all preferred habitat; the amount and quality of other available habitats may, by affecting survival rates of non-territorial birds, give rise to inter-island variation in group size (Faaborg et al. 1980). Unlike the mockingbirds, however, the hawks form groups through recruitment of adults from a non-territorial pool of non-breeders, rather than through delayed dis- persal. Additional demographic information is needed to determine whether habitat availability or inherent benefits of group living (e.g., Bednarz 1988) best accounts for the maintenance of hawk groups. Among the other landbirds, breeding ecology and social organization has been examined only in the ground finches (Geospiza spp.). The finches never maintain stable social groups, breeding instead in monogamous pairs on small all-purpose territories (Grant 1986). Helping in finches has been recorded only in one year when males of two species, Geospiza fortis and $G$. scandens, greatly outnumbered females on Daphne Major; all helpers were unpaired males attending nests of territorial neighbors (Price et al. 1983). Demographic differences between the mockingbirds and the finches are small (Curry and Grant 1989a) and probably cannot account for their divergent social systems. The finches differ from the mockingbirds in feeding ecology and territoriality: the habitat available for finch territories, even on an island such as Genovesa, represents a mosaic of patches varying in quality both spatially and temporally (Grant and Grant 1987). As a result, finches are subject to fewer constraints on dispersal and breeding (see Curry and Grant 1989a, b for more complete discussion). To varying degress, these finches also abandon their territories to form temporary feeding flocks in the dry season (Schluter 1984; Grant 1986), which suggests that they experience a more seasonally variable food supply than the omnivorous mockingbirds. Such variability may be associated with larger fluctuations in finch numbers, which would further inhibit the formation of stable social groups (Ford et al. 1988).

The different forms of social organization within Nesomimus fall within the range of variation exhibited by other mockingbirds (Mimus spp). Mainland populations of the northern mockingbird ( $M$. polyglottos) occupy a wide range of habitats and individuals can disperse over large distances (Kale and Jennings 1966). This species lives as simple pairs on all-purpose territories during the breeding season or, rarely, in polygynous trios (Laskey 1962; Logan and Rulli 1981; Breitwisch et al. 1986). Both the northern mockingbird and the Bahama mockingbird (M. gundlachii) similarly live in pair-only territories on islands in the northern Caribbean (Aldridge 1984; Curry, unpublished data). At least three of the seven South American species are more social. Groups of longtailed mockingbirds ( $M$. longicaudatus) larger than two persist during the breeding season in Ecuador, and joint nesting probably occurs (Marchant 1960). Chalk-browed mockingbirds (M. saturnin- 
$u s$ ) in Argentina usually breed in pairs, but helping behavior in groups of up to five adults has been documented (Fraga 1979). Tropical mockingbirds (M. gilvus) live in groups as large as five adults on mainland Venezuela (Skutch 1968), where both helping and joint nesting occur (E. Laurent, personal communication), and in groups of up to three on insular Bonaire (R.L. Curry, pers. obs.). These patterns illustrate that among mockingbirds, group territoriality and cooperative breeding are not unique to the Galápagos, or to island populations: highly social and less social populations both occur on islands as well as in mainland settings. Expanded comparative research on populations of Mimus would be a profitable route for further investigation of ecological influences on cooperative social organization.

Acknowledgements. Permission for this study was granted by the Programa Nacional Forestal (Ecuador), the Servicio Parque Nacional Galápagos, and the Charles Darwin Research Station; I give special thanks to Lcdo. Miguel Cifuentes A., Dr. Günther Reck, Jacinto Gordillo, and Franklin Salgado for facilitating local arrangements. World Wildlife Fund-US (grant 3182) provided primary financial support. My research was conducted in conjunction with P.R. Grant's studies of Galápagos landbirds; I gratefully acknowledge his contributions to all phases of the project. I also thank M.F. Kinnaird and S. Groves for providing unpublished data; D.J. Anderson, R. Brubaker, B.S. Coffman, C.B. Chappel, L.D. Hamilton, M. Iturralde, S.H. Stoleson, and S.W. Webb for field assistance; the Frank M. Chapman Fund, Sigma Xi, and The University of Michigan for financial support; R.D. Alexander, J.L. Brown, S.T. Emlen, H.A. Ford, J.D. Ligon, R.B. Payne, and R.W. Wrangham for comments on the manuscript; and S.H. Curry for support and encouragement. This is contribution 428 of the Charles Darwin Foundation for the Galápagos Islands.

\section{References}

Abbot I, Abbott LK (1978) Multivariate study for morphometric variation in Galápagos and Ecuadorean mockingbirds. Condor 80:302-308

Aldridge BM (1984) Sympatry in two species of mockingbirds on Providenciales Island, West Indies. Wilson Bull 96:603-618

Atkinson IAE (1985) The spread of commensal species of Rattus to oceanic islands and their effects in island avifaunas. In: Moors PJ (ed) Conservation of Island Birds. ICBP Technical Publication No 3, pp 35-81

Atwood JL (1980) Social interactions in the Santa Cruz Islad scrub jay. Condor $82: 440-448$

Austad SN, Rabenold KN (1985) Reproductive enhancement by helpers and an experimental inquiry into its mechanism in the bicolored wren. Behav Ecol Sociobiol 17:19-27

Austad SN, Rabenold KN (1986) Demography and the evolution of cooperative breeding in the bicolored wren, Campylorhynchus griseus. Behaviour 97:308-324

Bednarz, JC (1988) Cooperative hunting in Harris' Hawks (Parabuteo unicinctus). Science 239:1525-1527

Bowman RI, Carter A (1971) Egg-pecking behavior in Galapagos mockingbirds. Living Bird 10:243-270
Breitwisch R, Ritter RC, Zaias J (1986) Parental behavior of a bigamous male northern mockingbird. Auk 103:424 427

Brown JL (1969) Territorial behavior and population regulation in birds: a review and reevaluation. Wilson Bull $81: 293-329$

Brown JL (1974) Alternate routes to sociality in jays - with a theory for the evolution of altruism and communal breeding. Am Zool 14:63-80

Brown JL (1978) Avian communal breeding systems. Annu Rev Ecol Syst 9:123-155

Brown JL (1980) Fitness in complex avian social systems. In: Markl $\mathrm{H}$ (ed) Evolution of social behavior: hypotheses and empirical tests. Verlag Chemie, Weinheim, pp 115-128

Brown JL (1987) Helping and communal breeding in birds. Princeton University Press, Princeton

Brown JL, Brown ER (1980) Reciprocal aid-giving in a communal bird. Z Tierpsychol 53:313-324

Craig, JL (1984) Are communal pukeko caught in the prisoner's dilemma? Behav Ecol Sociobiol 14:147-150

Curry RL (1985). Breeding and survival of Galápagos mockingbirds during El Niño. In: Robinson $G$, del Pino $E$ (eds) El Niño in the Galápagos Islands: the event of 1982-1983. Charles Darwin Foundation for the Galápagos Islands, Quito, pp 449-471

Curry RL (1986) Whatever happened to the Floreana Mockingbird? Not Galapagos 43:13-15

Curry RL (1987) Evolution and ecology of cooperative breeding in Galápagos mockingbirds (Nesomimus spp.). $\mathrm{PhD}$ thesis, The University of Michigan

Curry RL (1988a) Influence of kinship on helping behavior in Galápagos mockingbrids. Behav Ecol Sociobiol $22: 141-152$

Curry RL (1988b) Group structure, within-group conflict and reproductive tactics in cooperatively breeding Galápagos mockingbirds, Nesomimus parvulus. Anim Behav 36:1708-1728

Curry RL, Anderson DJ (1987) Inter-island variation in blooddrinking by Galápagos mockingbirds. Auk 104:517-521

Curry RL, Grant PR (1989a) Demography of the cooperatively breeding Galápagos mockingbird in a climatically variable environment. J Anim Ecol 58:441-464

Curry RL, Grant PR (1989b) Galápagos mockingbirds: territorial cooperative breeding in a climatically variable environment. In: Stacey PB, Koenig WD (eds) Cooperative breeding in birds: long-term studies of ecology and behavior. Cambridge University Press, Cambridge (in press)

Eckhardt RC (1972) Intoduced plants and animals in the Galápagos Islands. Bio Science 22:585-590

Emlen ST (1978) The evolution of cooperative breeding in birds. In: Krebs JR, Davies NB (eds) Behavioural ecology. Sinauer, Sunderland, Mass, pp 245-281

Emlen ST (1982) The evolution of helping. I. An ecological constraints model. Am Nat 119:29-39

Emlen ST (1984) Cooperative breeding in birds and mammals. In: Krebs JR, Davies NB (eds) Behavioural ecology, 2nd edn. Sinauer, Sunderland, Mass, pp 245-281

Emlen ST, Vehrencamp SL (1983) Cooperative breeding strategies among birds. In: Brush AH, Clark GA Jr (eds) Perspectives in ornithology. Cambridge University Press, Cambridge, pp 93-120

Faaborg J, deVries Tj, Patterson CB, Griffin CR (1980) Preliminary observations on the occurrence and evolution of polyandry in Galápagos hawks (Buteo galapagoensis). Auk $98: 581-590$

Faaborg J, Patterson CB (1981) The characteristics and occurrence of cooperative polyandry. Ibis $123: 477-484$ 
Fitzpatrick JW, Woolfenden GE (1986) Demographic routes to cooperative breeding in some new world jays. In: Nitecki MH, Kitchell JA (eds) Evolution of animal behavior: paleontological and field approaches. Oxford University Press, New York, pp 137-160

Ford HA, Bell H, Nias R, Noske R (1988) The relationship between ecology and the incidence of cooperative breeding in Australian birds. Behav Ecol Sociobiol 22:239-249

Fraga RN (1979) Helpers at the nest in passerines from Buenos Aires Province, Argentina. Auk 96:606 607

Gayou DC (1986) The social system of the Texas green jay. Auk 103:540-547

Grant PR (1984) Extraordinary rainfall during the El Niño event of 1982-83. Not Galapagos 39:10-11

Grant PR (1985) Climatic fluctuations on the Galapagos Islands and their influence on Darwin's finches. Ornithol Monogr 36:471-483

Grant PR (1986) Ecology and evolution of Darwin's finches. Princeton Univ Press, Princeton

Grant PR, Boag PT (1980) Rainfall on the Galápagos and the demography of Darwin's finches. Auk 97:227-244

Grant PR, Grant BR (1987) The extraordinary E1 Niño event of 1982-83: effects on Darwin's finches on Isla Genovesa, Galápagos. Oikos 49:55-66

Grant PR, Grant N (1979) Breeding and feeding of Galápagos mockingbirds Nesomimus parvulus. Auk 96:723-736

Gulledge JL (1970) An analysis of song in the mockingbird genera Nesomimus and Mimus. MSc thesis, San Francisco State College, San Francisco

Hamann, O (1984) Changes and threats to the vegetation. In: Perry R (ed) Galápagos. Key Environments series, Pergamon Press, Oxford, pp 115-131

Harris MP (1973) The Galápagos avifauna. Condor $75: 265-278$

Hatch JJ (1966) Collective territories in Galápagos mockingbirds, with notes on other behavior. Wilson Bull 78:198-207

Hoeck HN (1984) Introduced fauna. In: Perry R (ed) Galápagos. Key Environments series, Pergamon Press, Oxford, pp 233-245

Kale HW II, Jennings WL (1966) Movements of immature mockingbirds between swamp and residential areas of Pinellas County, Florida. Bird-Banding 37:113-120

Kinnaird MF, Grant PR (1982) Cooperative breeding by the Galápagos mockingbird, Nesomimus parvulus. Behav Ecol Sociobiol 10:65-73

Koenig WD, Pitelka FA (1981) Ecological factors and kin selection in the evolution of cooperative breeding in birds. In: Alexander RD, Tinkle DW (eds) Natural selection and social behavior. Chiron, New York, pp 261-280

Koenig WD, Mumme RL (1987) Population ecology of the cooperatively breeding acorn woodpecker. Princeton Univ Press, Princeton

Laskey AR (1962) Breeding biology of mockingbirds. Auk 79:596-606

Logan CA, Rulli M (1981) Bigamy in a male mockingbird. Auk 98:385-386
McGowan, KJ, Woolfenden, GE (1989) A sentinel system in the Florida scrub jay. Anim Behav (in press)

Marchant S (1960) The breeding of some S.W. Ecuadorian birds. Ibis 102:349-381, 584-599

Orians GH, Orians CE, Orians KJ (1977) Helpers at the nest in some Argentine blackbirds. In: Stonehouse B, Perrins C (eds) Evolutionary ecology. University Park Press, Baltimore, pp 137-151

Plage D, Plage M (1988) Galápagos wildlife under pressure. Nat Geog 173:122-145

Price TD, Millington S, Grant PR (1983) Helping at the nest in Darwin's finches as misdirected parental care. Auk 101:192-194

Rabenold KN (1984) Cooperative enhancement of reproductive success in tropical wren societies. Ecology 65:871885

Reyer H-U (1980) Flexible helper structure as an ecological adaptation in the pied kingfisher (Ceryle rudis rudis L.) Behav Ecol Sociobiol 6:219-227

Robalino M (1985) Registros meteorologicos de la Estación Científica Charles Darwin para 1982-1983. In: Robinson G, del Pino E (eds) El Niño in the Galápagos Islands: the event of 1982-1983. Charles Darwin Foundation for the Galápagos Islands, Quito, pp 83-90

Rowley I (1965) Life history of the superb blue wren Malurus cyaneus. Emu 64:251-297

Schluter D (1984) Feeding and breeding correlates of social organization in two Galápagos finches. Auk 101:59-68

Selander RK (1964) Speciation in wrens of the genus Campylorhynchus. Univ Calif Publ Zool 74:1-305

Skutch AF (1968) The nesting of some Venezuelan birds. Condor 70:66-82

Stacey PB, Koenig WD, eds (1989) Cooperative breeding in birds: long-term studies of ecology and behavior. Cambridge Univ Press, Cambridge

Stacey PB, Ligon JD (1987) Territory quality and dispersal options in the acorn woodpecker, and a challenge to the habitat-saturation model of cooperative breeding. Am Nat 130:654-676

Swarth HS (1931) The avifauna of the Galapagos Islands. Occas Pap Calif Acad Sci 18:1-299

Trail PW (1980) Ecological correlates of social organization in a communally breeding bird, the acorn woodpecker, $\mathrm{Me}$ lanerpes formicivorus. Behav Ecol Sociobiol 7:83-92

Venables LSV (1940) Nesting behaviour of the Galápagos mockingbird. Ibis 82:629-639

Wiggins IL, Porter DM (1971) Flora of the Galápagos Islands. Stanford Univ. Press, Stanford

Woolfenden GE, Fitzpatrick JW (1984) The Florida scrub jay. Princeton University Press, Princeton

Zack S, Ligon JD (1985a) Cooperative breeding in Lanius shrikes. II. Maintenance of group-living in a nonsaturated habitat. Auk 102:766-773

Zack S, Ligon JD (1985b) Cooperative breeding in Lanius shrikes. I. Habitat and demography of two sympatric species. Auk 102:754-765 